\title{
Estudio de necesidades formativas en la restauración y rehabilitación del Patrimonio Histórico
}

INSTITUTO MUNICIPAL DE FORMACIÓN Y EMPLEO

Excmo. Ayuntamiento de Granada. Equipo Técnico Proyecto RAEDES

\section{INTRODUCCIÓN}

En la actualidad el Instituto Municipal de Formación y Empleo (IMFE) del Excelentísimo Ayuntamiento de Granada está desarrollando una actuación singularizada dentro del Proyecto INADTEC-Andalucía//I 00-Regiones de la iniciativa europea A.D.A.P.T., denominado "Proyecto RAEDES", proyecto piloto del sector de Bienes Culturales relativo a la restauración, rehabilitación y conservación del Patrimonio Histórico edilicio. Colaboran con el mismo, la Universidad de Granada a través del Centro de Formación Continua y el Patronato de la Alhambra y el Generalife.

Las principales líneas de actuación propuestas en la ejecución de este proyecto son las siguientes:

- Difusión adecuada de la conservación y restauración del patrimonio histórico para la sensibilización de los distintos sectores de la sociedad en favor de la recuperación edilicia.

- Formación de personas en todas las fases de desarrollo de las intervenciones en materia de restauración y rehabilitación de edificios, desde el puramente proyectual al artesano, pasando por la gestión y adecuación de nuevas iniciativas.

- Atención específica al conocimiento de los materiales tradicionales en la construcción, así como los tratamientos que demandan en su restauración sufriendo la mínima agresión.

- Recuperación de los oficios artesanos intervinientes en la rehabilitación tradicional, muy característicos de la zona.

- Búsqueda de fórmulas combinadas de formación-empleo que permitan en un tiempo no excesivo la incorporación de personal con diversos grados de cualificación al mercado laboral generado por el sector de a restauración y/o rehabilitación del patrimonio edilicio granadino.

Y en función de estas líneas de actuación, a través de un grupo interdisciplinar de técnicos en los distintos campos implicados (pedagogía, economía, derecho y arquitectura), se pretende conocer la problemática del sector, comprender el marco legal que regula y condiciona esta actividad y aportar los conocimientos necesarios para permitir la competencia profesional suficiente de sus beneficiarios que les reporte un aprendizaje permanente, así como, adaptarse a los cambios profesionales y tecnológicos que está experimentando la restauración y/o rehabilitación del Patrimonio Histórico edilicio.

\section{ESTUDIO DE NECESIDADES FORMATIVAS}

Se ha comenzado a elaborar un estudio de necesidades formativas, del cual podemos extraer las primeras conclusiones con carácter informativo y preliminar, debido a que este estudio aún permanece abierto y seguimos en la actualidad realizando los trabajos de campo en los distintos sectores con los que hemos contactado para realizarlo.

\section{OFERTA FORMATIVA DE GRANADA}

Este Estudio ha contemplado un periodo de tres años, es decir, de 1995-1997 (incluido este último), a través del que recogemos todas aquellas actividades, que en los distintos niveles educativos se han o están desarrollando en relación a nuestro objeto de estudio: la restauración y/o rehabilitación del Patrimonio Histórico edilicio.

De esta forma contamos con un inventario completo sobre:

- Cursos de doctorado de la Univ. de Granada,

- Varias titulaciones ofertadas por los planes de estudio de la Universidad de Granada, centrándonos más concretamente en la Licenciatura de bellas Artes en general y en las especialidades de Restauración y Diseño, en la Licenciatura de Historia del Arte, de la Escuela Universitaria de Arquitectura Técnica y la Escuela Técnica Superior de Arquitectura de esta Universidad.

- Todos aquellos cursos de Formación Profesional Ocupacional, relacionados con la construcción, aprobados y desarrollados en nuestra provincia, junto con otra gran diversidad de cursos de formación relacionados con este tema;

- La relación, ubicación y especialidades de las distintas Escuelas Taller y Casa de Oficios, aprobadas por el INEM;

- Y los planes formativos de la Fundación Laboral de la Construcción (con sede en Sevilla) demandados por distintos sectores empresariales de Granada.

Este estudio, en la actualidad, no se encuentra cerrado, puesto que tratamos en un ámbito de continua renovación e innovación en sus distintos niveles y la oferta formativa está en continuo proceso de elaboración y propuesta de diferentes y variados cursos relacionados con la restauraciónrehabilitación del Patrimonio Histórico granadino.

\section{ESTUDIO DE NECESIDADES DE FORMACIÓN}

Determinación de los distintos sectores, empresariales y profesionales, de análisis incluidos en este estudio, y elaboración del instrumento de medida

Elaboramos varios cuestionarios facilitados para su cumplimentación, así como entrevistas personalizadas, a sectores tan variados como:

- Empresas constructoras relacionadas con el ámbito de la restauración y/o rehabilitación.

- Empresas proveedoras en restauración y/o rehabilitación.

- Artesanos, abarcando gran diversidad de oficios implicados en este campo de la construcción.

- Arquitectos con experiencia en restauración y/o rehabilitación del Patrimonio Histórico edilicio granadino, y que en la actualidad conocen o desarrollan proyectos de esta índole. Y actualmente se está ampliando este estudio a al campo de los arquitectos técnicos, arqueólogos, licenciados en Bellas Artes, historiadores, y demás técnicos que intervienen en la restauraciónrehabilitación del Patrimonio Histórico.

- Y trabajadores, en cada uno de sus niveles profesionales y formativos (aprendices, peones, auxiliares, albañiles, oficiales, maestros, encargados, jefes de obra, delineantes, restauradores, licenciados en Historia del arte, licenciados en Bellas Artes, licenciados en Biología, arquitectos técnicos, arquitectos...), haciendo diferenciación, para el análisis, entre "empleados en la construcción", "desempleados con experiencia en la construcción" y "desempleados sin experiencia en la construcción" (siempre esta "construcción" referida al ámbito estudiado por nuestro programa).

Debido a lo ambicioso de esta propuesta y al escaso periodo de tiempo en el que se viene desarrollando, no podemos ofrecer conclusiones definitivas, tan sólo proporcionar un avance de aquellos datos, que a nuestro modo de ver, pueden ir dejando entrever importantes necesidades formativas a las que podemos comenzar a plantear soluciones eficaces y satis- 
factorias para todos y cada uno de los que nos encontramos inmersos el tema de la restauración y/o rehabilitación del Patrimonio Histórico edilicio.

\section{Primeras conclusiones obtenidas hasta el momento actual de la investigación}

Existen pocas empresas y profesionales del sector de la construcción dedicadas al subsector de la restauración y/o rehabilitación. Siendo conveniente señalar, en la mayoría de los casos, el carácter polivalente del trabajo desempeñado por estos sectores estudiados, puesto que la mayoría trabajan mayoritariamente en el campo de la construcción en general y sólo una minoría está especializada en rehabilitación.

Los cuestionarios, en la mayoría de los casos se entregaron en mano, especialmente los destinados a los trabajadores. La remisión de cuestionarios ha sido minoritaria debido en gran parte a la poca predisponibilidad de los empresarios, artesanos y profesionales de la construcción a colaborar en este tipo de trabajo y posiblemente a la saturación de encuestas a las que se ven sometidos por distintos organismos, instituciones y programas. Factores que por otra parte ralentizan nuestra investigación.

Aún así, se han detectado necesidades de formación en prácticamente todos los niveles profesionales a los que se accedido (constructores, gerentes, administrativos, arquitectos, arquitectos técnicos, encargados de obra, albañiles y peones) siendo considerable el porcentaje de encuestados que no han detectado necesidades de formación en el desempeño de se trabajo, ni en el rendimiento de los trabajadores que pertenecen a sus empresas.

\section{PROPUESTA DE CURSOS DE FORMA- CIÓN A PARTIR DEL ESTUDIO DE LA OFERTA FORMATIVA ACTUAL Y LAS NECESIDADES ENCONTRADAS EN ESTE ESTUDIO}

En función de las conclusiones obtenidas en este Estudio Preliminar, podemos adelantar la propuesta de una serie de cursos de formación emergentes de esta primera exposición de resultados.
Destacamos la importancia que tiene, para estos sectores relacionados con la restauración-rehabilitación, que los cursos que se les oferten tengan temáticas tales como:

- Ensayos no destructivos para el diagnóstico en la recuperación edilicia.

- Tapiales.

- Documentación, archivos y catalogación del Patrimonio Histórico. Técnicas de investigación.

- Revestimientos tradicionales. Morteros de cal.

- Revocos y estucos.

- Derribos y demoliciones en rehabilitación.

- Consolidación de estructuras de madera. Tratamientos de limpieza de la madera.

- Introducción de instalaciones en edificios antiguos.

- Seguridad e higiene en el trabajo

- Legislación.

\section{Información:}

Av. Divina Pastora, 7 y 9 (Bajos)

I80I2 Granada. Tel. 958/279690

Fax. 958/80 5I 56

Internet: http://www.imfegranada.es

E-mail: adapt@imfegranada.es

\section{FORMACIÓN: ORGANISMOS E INSTITUCIONES El Centro de Estudios en Museo de la Institución Smithsonian}

El Centro de Estudios en Museos (CMS) es una sección de la Institución Smithsonian destinada a la investigación, formación, información y servicios profesionales en esta materia. Su misión es ayudar a los museos de los Estados Unidos y del extranjero a cumplir con sus objetivos como servicios públicos. El personal del Centro lo forman profesionales de los museos, estudiantes, voluntarios y especialistas en recursos culturales. Mediante sus programas y publicaciones el Centro promueve foros para desarrollar la imaginación y ampliar la comprensión, vinculando a personas, lugares e instituciones mediante el diálogo y el debate, buscando los puntos en común.

El Centro de Estudios en Museos (CMS) desarrolla los siguientes programas:

\footnotetext{
- Programa de Estudios de Museos de Indios Americanos, para responder a las necesidades formativas de los profesionales que trabajan en museos tribales y centros culturales de indios americanos.
}

- Estancias en prácticas en los museos y galerías de la Smithsonian, destinadas a nacionales y extranjeros, cuya información detallada puede consultarse en la publicación Internship Opportunities at the Smithsonian Institution que facilita el CMS.

- Seminario para directivos de museos: curso anual con un programa de cinco días de duración.

- Boletín CMS, publicación que informa sobre las investigaciones y trabajos desarrollados por el CMS.

- Becas para investigación en la practica de Museos, que permite a los profesionales de los museos acometer investigaciones en teoría y gestión de museos, usando los recursos y ventajas que ofrece la Sthmisonian.

- Becas para estudiantes graduados en estudios latinos.

- Interpretación de las cultural latinas: investigación y museos: es un programa interuniversitario consistente en un seminario de dos semanas de duración, sobre métodos de investigación de museos y conservación de colecciones.
- Programa de becas para estancias en museos, para fomentar la vocación de estudiantes de diversos sustratos culturales interesados en dedicarse profesionalmente a los museos.

- Centro de Referencia de Museos, es un centro de información de las Bibliotecas Stmisonian que ofrece datos sobre organismos de museos, museos en Internet, becas, recursos educativos, profesionales $y$ de conservación, etc.

(Email:libmail@sil.si.edu)

- Base de datos de estudios en museos, con información bibliográfica sobre teoría y práctica museológica en gestión de colecciones, técnicas expositivas, y estudios de evaluación.

\section{Información:}

Center for Museum Studies

900 Jefferson Drive, SW

Room 2235 - MRC 427

Smithsonian Institution

Washington, D.C. 20560

http://www.si.edu 